\title{
ECMI in global and european scenarios
}

\author{
Vincenzo Capasso • Matti Heiliö
}

Received: 29 November 2010 / Accepted: 3 June 2011 / Published online: 3 June 2011

(C) 2011 Capasso, Heiliö; licensee Springer. This is an Open Access article distributed under the terms of the Creative Commons Attribution License

Modelling, systems analysis and simulation are tools for R\&D and keys for achieving competitive edge. Emerging mathematical technology presents a challenge for university education and research collaboration. This vision inspired the inception of an international cooperative network, the European Consortium for Mathematics in Industry. In 1985 a meeting in Amsterdam organized by Michiel Hazewinkel, Brenny van Groesen, and Robert Mattheij was named ESMI, European Symposium on Mathematics in Industry. Besides being scientifically successful, the groundwork was laid to establish a European organization. In 1986, under the leadership of Helmut Neunzert, ECMI (the European Consortium for Mathematics in Industry) was founded in Mussbach, as a Dutch Stichting. ECMI has a three-fold mission: to promote the use of mathematics in industry, to educate young industrial mathematicians, and to operate on a European scale. The first objective is quite vivid and has gained momentum even on a worldwide scale as many initiatives for bringing mathematics to industry have become fruitful undertakings, through meetings, study groups, special programmes and even special institutes, where funding from industry is has been and will continue to be essential. The second part of the mission has been the major avenue of action and achievement of ECMI. By pooling ideas and expertise ECMI established

\footnotetext{
V Capasso $(\bowtie)$

ADAMSS (Interdisciplinary Centre for Advanced Applied Mathematical and Statistical Sciences), Universitá degli Studi di Milano, Milano, Italy

e-mail: vincenzo.capasso@unimi.it

V Capasso

Department of Mathematics, Universitá degli Studi di Milano, Via Saldini 50, 20133 Milano, Italy

M Heiliö ( $\varangle$ )

Department of Mathematics and Physics, Lappeenranta University of Technology, Box 20, 53851

Lappeenranta, Finland

e-mail: matti.heilio@lut.fi
} 
in early 90's an educational program Mathematics for Industry. It is a prototype or model curriculum on the MS level and can be seen as anticipation of the Bologna scheme. Several European universities have adopted MS-programs in Technomathematics, Industrial Mathematics or their equivalent. EU-funded projects have been initiated to boost international cooperation in curriculum development. An Erasmus Mundus programme (ESIM) and more recently a European Erasmus Curriculum development project (ECMIMIM) have been carried out with an objective to create an updated model curriculum for a European Master education geared towards the use of mathematics in industry and applied sciences. Currently several institutions, spread out over ten European countries, are working together on a programme that may take away a bit of their local freedom in favor of building a really transnational common curriculum. This is quite impressive compared to what many other European cooperative programmes have realized thus far. The ECMI educational programme is clearly a success; ECMI has received substantial recognition as evidenced in various articles that have appeared in the press. The third objective has induced many cooperative efforts, quite often not even within the ECMI framework directly, but undoubtedly inspired by or fostered by it.

\section{ECMI and European Strategic Scenarios}

The European Union has committed itself to strategic initiatives promoting open and transparent flow of knowledge and innovative processes. European Research Area (ERA) is aimed at making Europe a place where scientific research, technological development and innovation thrive in order to address the major challenges of our times. http://ec.europa.eu/research/era The European Higher Education Area (EHEA) is the main objective of the Bologna Process and is meant to ensure more comparable, compatible and coherent systems of higher education in Europe. http://www.ehea.info/ In a recent CEPS report (Centre for European Policy Studies http://aei.pitt.edu/14482/) the following statement (by Maria Anvret) captures the mission "Today, nothing is more important for the re-launch of the EU project than unleashing the potential for EU competitiveness through innovation". A recently published EU 2020 agenda defines a strategy for smart, sustainable and inclusive growth. http://ec.europa.eu/eu2020/indexen.htm At the focal plane of the European Research and Innovation Strategy are key enabling technologies. These are defined by the following features: They are i) knowledge-intensive; ii) associated with highly-skilled employment; iii) multi-disciplinary, cutting across many technology areas; iv) create multiplier effects v) enable innovation, and are of systemic relevance to economies. The above description puts mathematics clearly on the global (and hopefully European) strategic map. Mathematics, modelling and computational simulation presents a novel technological paradigm which satisfies all criteria of an enabling technology. It provides a framework for the analysis, optimization, and control of industrial processes. The promotion of European collaboration and network effects in industrial mathematics is obviously aligned with the European strategies (ERA and EHEA). ECMI has been acting in this spirit for a full decade prior to these formal strategy statements. The common challenge for industry and the mathematical community is 
to inseminate corporate foresight by translating trends in future research into the real world of strategic management.

\section{ECMI Mission}

It should be noticed, however, that the European formula of ECMI is much less unique than in the early days, as there are a few other consortia who also work on some sort of cooperation between industry and mathematically oriented institutes (albeit in narrower areas). Today's problems are complex and nonlinear, they involve multiple length and time scales, and their analysis requires mathematics beyond textbooks and novel algorithms and software tools. Modern measurement technology and ICT means access to torrential supply of information and ingenious use of mathematics means exploiting this to full extent. This is the spinal chord of new value added networks, a knowledge-based economy, convergence of technologies and ubiquitous intelligence. A technology arena and a global world offers major challenges: energy and resource reversal scenarios, climate change and other environmental impacts, clean technology, energy efficiency/security, food security, smart cities (congestion, traffic control), intelligent electricity grids, delivery networks and consumer services. ECMI basic ideas have been implemented in the following activities:

\section{Conferences}

Conferences are an important and integral part of ECMI activities. They ensure timely distribution of ideas and thoughts and provide a forum where supply and demand can meet. In view of their special role, ECMI conferences are focused on applications rather than on mathematical subjects. An ECMI conference is held every two years, attended by academic applied mathematicians and industrial scientists, the latter comprising about 25 per cent of the total attendance. The goals of an ECMI Conference are in synthesis:

- to provide a forum for those who are either actively involved or generally interested in mathematics in industry;

- to serve as a venue for ECMI members at large;

- to explore new and relevant industrial areas where mathematics plays a role.

\section{Industry Days}

These day-long workshops are held several times a year at various ECMI centres to strengthen links between ECMI and local industries.

\section{Special Interest Groups}

Special interest groups play a key role in the research branch of ECMI. They are typically application-oriented, and provide a forum across boundaries, where a single 
European country may be too small. They have turned out to be a successful means for letting industrialists discuss relevant actual problems with mathematicians, thus increasing knowledge for the first and expertise for the second. Successful SIGs have been organized on glass, polymers, multibody dynamics, shape and size in Biotech and Material Science, and so on. SIG's organize a series of activities for dissemination of outcomes of collaborative research.

\section{European Study Groups with Industry}

These week-long meetings treat a limited number of problems from industrial companies of current interest are modelled and analyzed. European study groups, pioneered by University of Oxford, have been held for many years. These are genuine brainstorming sessions on real problems, the only formal sessions being at the beginning and the end of the week. The spin-off is substantial in terms of contacts with industry and genuine mathematical problems. The objectives are

- to stimulate academics by working on problems that are both new and relevant and often present exciting mathematical challenges;

- to introduce students to industrial research in action;

- to provide recruitment possibilities for students.

EU grants and postdoctoral fellowships have been important for maintaining and strengthening its research base and collaborative links between centres. European Study Groups offer opportunities for young researchers to work on mathematical problems in industry at doctoral and postdoctoral level. This is a unique possibility to learn from complementary expertise at the various centres.

\section{ECMI Educational Programme}

The central aim of the programme 'Mathematics for Industry' is to offer to master students in mathematics and other closely related fields a training for acquiring, on the one hand, a broad knowledge of mathematical techniques and, on the other, the ability to use these techniques for solving industrial problems. The Programme aims at developing both aspects, and an emphasis is placed on constructive mathematical techniques. The ability to use mathematical techniques for industrial problems entails modelling and analytical skills, and the capability to work with people from different disciplines.

\section{The ECMI Modelling Weeks}

As part of the ECMI educational programme 'Mathematics in Industry', ECMI organizes modelling weeks, that is, week-long meetings for training master students in modelling problems arising in industry. Students coming from different centres (about 40 per year) are organized into interdisciplinary and international teams of 4-5 members to respond to a problem posed by an instructor who simulates a real industrial delegate. The main objectives are then: 
- to simulate an industrial environment;

- to foster working in groups with heterogeneous background;

- to enhance communication skills, with presentation of results orally, and by a written report, prepared at home, in collaboration via internet;

- to favour social contacts and knowledge about local habits (including history and food) of different regions of Europe.

\section{Editorial Activities}

- The ECMI Newsletter is published twice a year. Its aim is to make a picture of what is going on especially in member institutions regarding university-industry inter-action in applied mathematics. Case histories, reports of workshops, survey articles and important events and initiatives are presented.

- The ECMI book series, which was established from the very beginning in order to host proceedings of ECMI activities, such as the ECMI Conferences, the SIG's workshops, and monographs, is currently successful running as a subseries of the Springer book series on Mathematics in Industry.

- The Journal on Mathematics in Industry. Finally, with this issue, ECMI has started another important initiative, in collaboration with Springer, whose aims confirm the mission of ECMI of establishing a permanent communication channel between advancement of mathematics and industrial needs of innovation.

We wish to stress that, as usual, all ECMI editorial actions are open to authors from all countries worldwide, as part of a cooperative effort. In order to further advance the role of Mathematics in Industry at a global level, ECMI has started, or has played a major role within various targeted initiatives, some of which are described below.

\section{ECMI in the Global Scenario}

\subsection{Macsinet}

During 2000-2004, as a joint venture of ECMI and ECCOMAS, MACSI-net was set up as an EU supported European Network of Excellence, aiming to further the deployment of applied mathematics and computing to meet the needs of European industry. It was funded by the European Union, within the Fifth Framework Programme, in particular IST (Information Society Technologies). The major task was to charter the opportunities for cooperation between academia and industry and to study how this co-operation could be promoted in the area of applied mathematics and computing in particular.

\section{EMS (European Mathematical Society)}

Membership in the EMS has been acquired in order to help in combining forces in Europe to achieve more visibility for Mathematics. ECMI members are among the most active within the EMS Applied Mathematics Committee; in particular the Chairman of that committee is a member of the ECMI Council. 


\section{OECD (Organisation for Economic Co-operation and Development)}

ECMI has also played a major role in the organization of the workshop on 'Mathematics in Industry' which was held in Heidelberg, Germany, on March 22-24, 2007, as part of the activities of the OECD (Organisation for Economic Co-operation and Development)-Global Science Forum. The objectives of the workshop were

(1) to analyse the relationship between the mathematical sciences and industry in the participating countries;

(2) to identify significant trends in research in the mathematical sciences in academia and the mathematical challenges faced by industry in the globalised economic environment, and analyse the implications of the trends for the relationship between mathematical scientists in academia and industry;

(3) to identify and analyse major challenges and opportunities for a mutually beneficial partnership between industry and academia; and

(4) to formulate action-oriented practical recommendations for the main stakeholders: the community of mathematical scientists, participating industries and governments.

Its report, available at http://www.oecd.org/dataoecd/47/1/41019441.pdf summarises the deliberations and presents the findings and recommendations of the workshop and follow-up consultations among the participants.

\section{ESF (European Science Foundation)}

As a follow up of the OECD Report, an ESF Forward Look programme on 'Mathematics in Industry' has been activated by the EMS Applied Mathematics Committee; the programme is run in strict cooperation with ECMI, and indeed many of its group leaders are members of the ECMI Council. It can be really seen as a possible and important amplifier of ECMI activities in the whole European Research Area, and an important vehicle for including Industrial Mathematics in the EU Framework Programmes.

\section{ICIAM (International Council for Industrial and Applied Mathematics)}

ECMI is an active member of ICIAM, and indeed a member of the ECMI Council has been recently elected in the Board of ICIAM.

Further information about ECMI can be found at http://www.ecmi-indmath.org 